\title{
Effect of Filling Interval Time on Long-Term Mechanical Strength of Layered Cemented Tailing Backfill
}

\author{
Shuai Cao ${ }^{1,2}$ and Wei-dong Song ${ }^{1,2}$ \\ ${ }^{1}$ School of Civil and Environmental Engineering, University of Science and Technology Beijing, Beijing 100083, China \\ ${ }^{2}$ State Key Laboratory of High-Efficient Mining and Safety of Metal Mines of Ministry of Education, \\ University of Science and Technology Beijing, Beijing 100083, China
}

Correspondence should be addressed to Shuai Cao; sandy_cao@foxmail.com

Received 18 August 2016; Accepted 3 October 2016

Academic Editor: Yuri Ribakov

Copyright (C) 2016 S. Cao and W.-d. Song. This is an open access article distributed under the Creative Commons Attribution License, which permits unrestricted use, distribution, and reproduction in any medium, provided the original work is properly cited.

\begin{abstract}
To explore the influence that filling interval has on the mechanical strength of layered cemented tailing backfill (LCTB), uniaxial compression test is conducted on LCTB samples with a concentration of 70\%, 72\%, and 75\% and a filling interval of $12 \mathrm{~h}, 24 \mathrm{~h}, 36 \mathrm{~h}$, and $48 \mathrm{~h}$. From the tests above, mechanical properties and failure modes of LCTB are acquired. The results are as follows: (1) The peak compressive strength of LCTB decreases as the filling interval increases, and it increases when the concentration grows with a certain length of filling interval. At the same time, the peak compressive strength and filling interval show polynomial distribution. (2) There are four stages during the loading process of cemented backfill specimen, that is, compression stage, linear elastic stage, crack extension stage, and undermines development stage. As the filling interval increases, CTB shows a failure mode of tensile failure-tensile shear failure transition-tensile and shear mixing destruction, which provides a theoretical basis for strength design and stability control of backfill.
\end{abstract}

\section{Introduction}

With the rapid development of underground mining technology and the gradual growth in production capacity of the mine, high-intensity mining will surely become a trend in the future [1]. Compared with caving method, filling method has shown significant effect in the control of surface subsidence $[2,3]$.

Being classified into sublevel open stoping and stage open stoping according to the stage height, sublevel open stoping with subsequent backfilling is being more and more widely used because of its safety and efficiency. A giant goaf is formed in a short period of time when this method is applied efficiently. Limited by the present filling capacity, it is almost impossible to accomplish filling process in such a large scale all at once. Thus, the stratification of backfilling appears. Things like that happen in large metal mines in China, such as Dongguashan Copper Mine, Daye Iron Mine, and Xiadian Gold Deposits. At present, researches at home mainly focus on integrated filling specimen, using methods like laboratory tests, numerical simulation, and theoretical modeling [4-8]. The creep characteristics and hardening characteristics of fill paste are studied by Chen et al. [9], and the results show that as stress level of the fill paste grows, the strain rate in elastic stage decreases and the instantaneous modulus of deformation increases. Using the central composite experimental method, Li et al. [10] study the influences that cement and fine gangue have on filling specimens' strength characteristics with different curing periods. And the response surface regression model of filling strength with different curing periods is established as well. $\mathrm{Xu}$ et al. [11] study the variation of specimens' stress-strain, resistivity, and temperature during the uniaxial compression process and the abnormal precursor in the instability and destruction process of specimen. Ma et al. [12] study the fracture behavior of polypropylene fiber reinforced filling paste material through macro-micro method, and the results show that the tenacity and strain corresponding to peak intensity point are improved significantly because of the fiber. However, researches above have not given consideration to 
TABLE 1: Chemical component of classified tailings.

\begin{tabular}{lccc}
\hline Ingredient & Content/\% & Ingredient & Content $\%$ \\
\hline $\mathrm{SiO}_{2}$ & 65.7 & $\mathrm{P}$ & 0.08 \\
$\mathrm{Al}_{2} \mathrm{O}_{3}$ & 14.3 & $\mathrm{Fe}$ & 3.05 \\
$\mathrm{CaO}$ & 1.88 & $\mathrm{~S}$ & 0.13 \\
$\mathrm{MgO}$ & 0.49 & $\mathrm{Au}$ & $\leqq 0.01$ \\
\hline
\end{tabular}

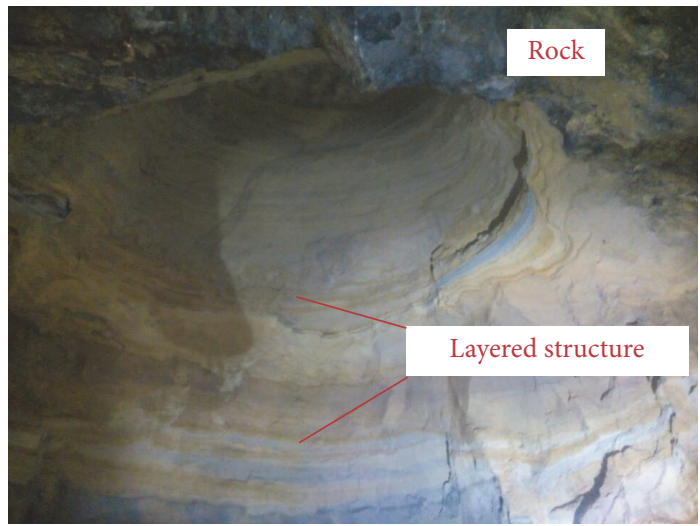

FIGURE 1: Stratification phenomenon of tailings backfill.

the influence that the structure has on mechanical strength of specimen. Professor Cai has studied the stratification in cemented block rock filling, but no laboratory tests are conducted [13]. Taking the stratification in backfilling into consideration, Cao et al. [14] conduct tests on backfill specimen. And the results show that the specimen shows stronger weakening effect as filling times increase.

Based on the analysis on classified tailings particle diameter, cemented specimens are made using transparent plastic mold. To explore the influence that the filling interval has on mechanical strength of the specimen, with the cement-sand ratio of $1: 6$, the filling interval of $12 \mathrm{~h}, 24 \mathrm{~h}, 36 \mathrm{~h}$, and $48 \mathrm{~h}$, and the concentration of $70 \%, 72 \%$, and $75 \%$, the variation of the compressive strength and the failure mechanism are studied.

\section{Experimental Research}

2.1. Backgrounds. In terms of Chinese metal mines, the stratification is obvious whether in subsequent cemented filling or in cut and fill mining method filling. Figure 1 shows the stratification phenomenon in a gold mine in Shandong, China.

2.2. Materials and Equipment. Taking the classified tailings from a gold mine and the $\mathrm{C}$ type rubber aggregate as materials, particle diameter composition is analyzed using the laser particle size analyzer after all samples are dried and milled uniformly. The results are shown in Figure 2.

The samples are made of tailings by splitting method and then chemical analysis is conducted on them. The results are shown in Table 1.

The size distribution curve of classified tailings is shown in Figure 2. We can see that the particle composition is $D_{10}$ $=30.74 \mu \mathrm{m}, D_{90}=190.04 \mu \mathrm{m}$, and $D_{50}=100.54 \mu \mathrm{m}$, and the

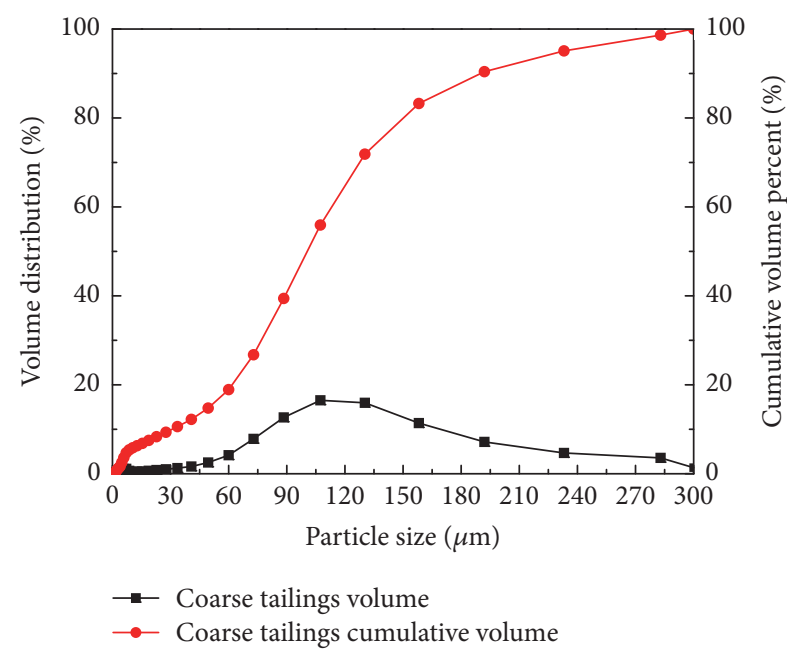

FIgURE 2: The tailings particle size distribution curve.

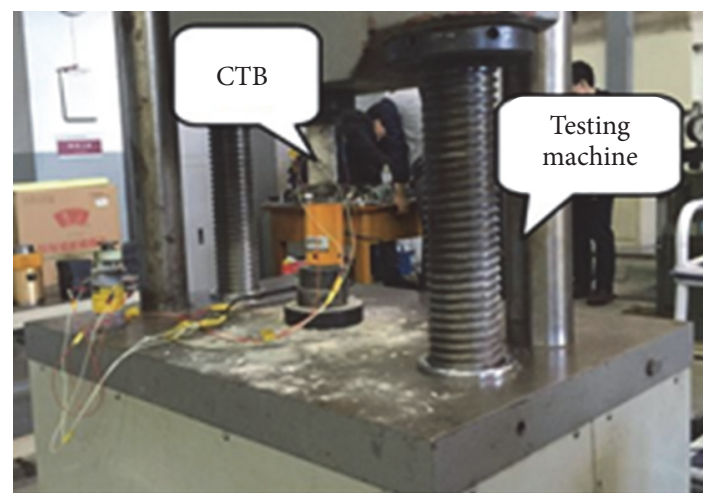

FIGURE 3: Equipment of uniaxial compressive test.

specific surface area is $1601.58 \mathrm{~cm}^{2} / \mathrm{cm}^{3}$, which indicates that it typically belongs to coarse tailings.

The purpose of considering the chemical composition of filling material is to study the influence it has on backfill. From Table 1, it can be seen that the chemical composition of tailings includes $\mathrm{SiO}_{2}, \mathrm{Al}_{2} \mathrm{O}_{3}, \mathrm{Fe}, \mathrm{CaO}, \mathrm{S}$, and Au. Alkalinity coefficient is used to evaluate the quality of tailings, and the value is 0.026 , which is far more less than 1 . Thus, the tailings typically belong to acidic slag. Among them, $\mathrm{SiO}_{2}$ and $\mathrm{Al}_{2} \mathrm{O}_{3}$ are not conducive to the mechanical strength of cemented backfill.

High transparent plastic tube is processed to cylindrical mold to make specimens, with a diameter of $46 \mathrm{~mm}$ and a height of $100 \mathrm{~mm}$.

Universal testing machine is used in stress load test (shown in Figure 3), and the load-displacement data are obtained by data logger and saved as text files.

2.3. Test Scheme and Assumption. To explore the influence that the filling interval has on mechanical strength of the specimen, the difference caused by filling interval needs to be taken into consideration. Set the cement-sand ratio as $1: 6$, the concentration as $70 \%, 72 \%$, and $75 \%$, the temperature as $25^{\circ} \mathrm{C}$, 
TABLE 2: The uniaxial compressive strength of filling material for different layers (unit: MPa).

\begin{tabular}{|c|c|c|c|c|c|c|c|}
\hline $\begin{array}{l}\text { Specimen } \\
\text { number }\end{array}$ & $\begin{array}{c}\text { Peak } \\
\text { strength/MPa }\end{array}$ & $\begin{array}{c}\text { Specimen } \\
\text { number }\end{array}$ & $\begin{array}{c}\text { Peak } \\
\text { strength/MPa }\end{array}$ & $\begin{array}{c}\text { Specimen } \\
\text { number }\end{array}$ & $\begin{array}{c}\text { Peak } \\
\text { strength/MPa }\end{array}$ & $\begin{array}{c}\text { Specimen } \\
\text { number }\end{array}$ & $\begin{array}{c}\text { Peak } \\
\text { strength/MPa }\end{array}$ \\
\hline $70-12-1$ & 1 & $70-24-1$ & 4.73 & $70-36-1$ & 3.81 & $70-48-1$ & 3.96 \\
\hline $70-12-2$ & 4.51 & $70-24-2$ & 3.25 & $70-36-2$ & 4.34 & $70-48-2$ & 2.5 \\
\hline $70-12-3$ & 4.34 & $70-24-3$ & 4.42 & $70-36-3$ & 3.93 & $70-48-3$ & 3.31 \\
\hline $70-12-4$ & 4.71 & $70-24-4$ & 4.13 & $70-36-4$ & 4.17 & $70-48-4$ & 3.82 \\
\hline $70-12-5$ & 3.56 & $70-24-5$ & I & $70-36-5$ & 2.96 & $70-48-5$ & 3.82 \\
\hline $70-12-6$ & I & $70-24-6$ & 3.27 & $70-36-6$ & 4.41 & $70-48-6$ & I \\
\hline Average & 4.28 & Average & 3.95 & Average & 3.93 & Average & 3.48 \\
\hline $72-12-1$ & 4.27 & $72-24-1$ & 3.63 & $72-36-1$ & 4.15 & $72-48-1$ & 4.69 \\
\hline $72-12-2$ & 1 & $72-24-2$ & 5.02 & $72-36-2$ & 3.59 & $72-48-2$ & 3.06 \\
\hline $72-12-3$ & 4.61 & $72-24-3$ & I & $72-36-3$ & 3.79 & $72-48-3$ & 3.93 \\
\hline $72-12-4$ & 4.06 & $72-24-4$ & 4.59 & $72-36-4$ & I & $72-48-4$ & 5.24 \\
\hline $72-12-5$ & 4.23 & $72-24-5$ & I & $72-36-5$ & 4.55 & $72-48-5$ & 3.57 \\
\hline $72-12-6$ & 4.11 & $72-24-6$ & 3.68 & $72-36-6$ & 4.84 & $72-48-6$ & 3.82 \\
\hline Average & 4.26 & Average & 4.23 & Average & 4.18 & Average & 4.05 \\
\hline $75-12-1$ & 4.39 & $75-24-1$ & 5.89 & $75-36-1$ & I & $75-48-1$ & 4.98 \\
\hline $75-12-2$ & 5.69 & $75-24-2$ & 3.84 & $75-36-2$ & 4.96 & $75-48-2$ & 5.49 \\
\hline $75-12-3$ & 5.68 & $75-24-3$ & 5.73 & $75-36-3$ & 5.33 & $75-48-3$ & 5.71 \\
\hline $75-12-4$ & 5.54 & $75-24-4$ & 5.42 & $75-36-4$ & 6.01 & $75-48-4$ & 5.17 \\
\hline $75-12-5$ & 6.29 & $75-24-5$ & 6.07 & $75-36-5$ & I & $75-48-5$ & 5.25 \\
\hline $75-12-6$ & 5.85 & $75-24-6$ & 6.25 & $75-36-6$ & 5.54 & $75-48-6$ & 5.05 \\
\hline Average & 5.57 & Average & 5.53 & Average & 5.46 & Average & 5.28 \\
\hline
\end{tabular}

Note: " $/$ " is the largest value of the results and the average of strength value is calculated to promote a culling process.

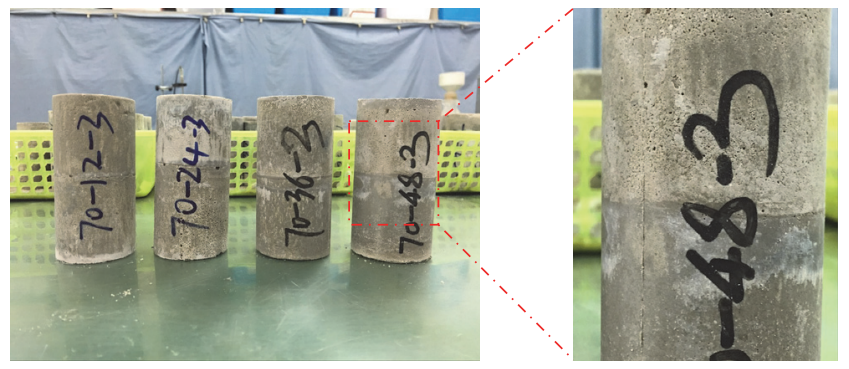

FIGURE 4: Layered cemented backfill specimens.

and the curing period as $60 \mathrm{~d}$. To reduce the influence caused by different filling interval, long-term strength of cemented backfill is studied.

\section{Results and Analysis}

To explore the relationship between the mechanical strength and filling interval, taking filling interval and concentration into consideration, the uniaxial compression test is conducted. The results are shown in Table 2 and the specimens are shown in Figure 4.

It can be seen from Table 2 that the uniaxial compressive strength shows a growth trend as the filling interval increases. The uniaxial compressive strength increases as the concentration grows when the filling interval is set as a certain value.

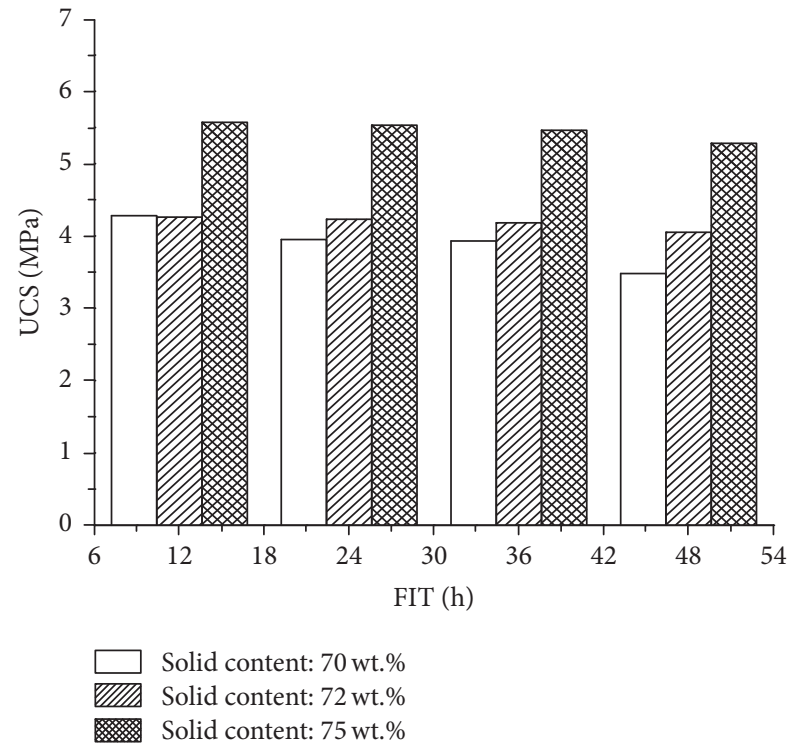

FIGURE 5: Relationship between uniaxial compressive strength and filling interval.

3.1. Quantitative Relationship between Filling Interval and Peak Compressive Strength. Figure 5 shows the relationship between filling interval and the peak compressive strength. It can be seen from the picture that uniaxial compressive 
TABLE 3: Multiple correlation coefficient result of different fitting methods.

\begin{tabular}{lcccc}
\hline \multirow{2}{*}{ Concentration } & \multicolumn{4}{c}{ Fitting way } \\
& Linear & Exponential & Logistic & Polynomial \\
\hline 70 & 0.9042 & 0.8963 & 0.8504 & 0.9154 \\
72 & 0.8961 & 0.8923 & 0.7575 & 0.9930 \\
75 & 0.8943 & 0.8903 & 0.7544 & 0.9935 \\
Average & 0.8982 & 0.8930 & 0.7874 & 0.9673 \\
\hline
\end{tabular}

strength decreases as the filling interval increases. When filling interval is set as a certain value, the specimens with a concentration of $75 \%$ show higher strength compared with those with concentration of $70 \%$ and $72 \%$. Setting the filling interval of $24 \mathrm{~h}$ as an example, the value of uniaxial compressive strength is $3.95 \mathrm{MPa}$ when the concentration is $70 \%$. And the values are, respectively, $4.23 \mathrm{MPa}$ and $5.53 \mathrm{MPa}$ corresponding to the concentration of $72 \%$ and $75 \%$.

To analyze the quantitative relationship between the strength of backfill and filling times, the results obtained according to four kinds of filling intervals are fitted in four ways including linear fit, exponential fit, logistic fit, and polynomial fit. The multiple correlation coefficient $R^{2}$ is obtained and the results are shown in Table 3.

It can be obtained from Table 3 that the multiple correlation coefficients for the four fitting ways above are relatively high when the concentration is $70 \%$. The values are, respectively, $0.9042,0.8963,0.8504$, and 0.9154 corresponding to the linear fit, exponential fit, logistic fit, and polynomial fit. Among them, polynomial fit has the best fitting effects. When the concentration is $72 \%$, the multiple correlation coefficient of logistic fit is the lowest and the polynomial fit is the highest with a value of 0.9930 . Besides, the values of linear fit and exponential fit are rather similar. The fitting effects are generally good when the concentration is $75 \%$, among which the polynomial fit is the best with a value of 0.9673 . Thus, it can be seen that polynomial fit can characterize the quantitative relationship between uniaxial compressive strength and filling interval better, which can be shown in

$$
\mathrm{UCS}=a(\mathrm{FIT})^{2}+b(\mathrm{FIT})+c,
$$

where UCS is the uniaxial compressive strength of cemented backfill specimens, whose unit is hour and $a, b$, and $c$ are coefficients related to uniaxial compressive strength and filling interval.

\subsection{Relationship between Concentration and Peak Compres-} sive Strength. To figure out the influence that the concentration has on the strength of cemented backfill, the concentration-uniaxial compressive strength curve is drawn, which is shown in Figure 6.

It can be obtained from Figure 6 that the peak compressive strength shows an increasing trend as the concentration grows. Taking the filling interval of $36 \mathrm{~h}$ and $48 \mathrm{~h}$ as an example, the peak strength is $3.93 \mathrm{MPa}$ with a filling interval of $36 \mathrm{~h}$ and a concentration of $70 \%$. But the peak strength changes into $3.48 \mathrm{MPa}$ when the interval is $48 \mathrm{~h}$, which shows

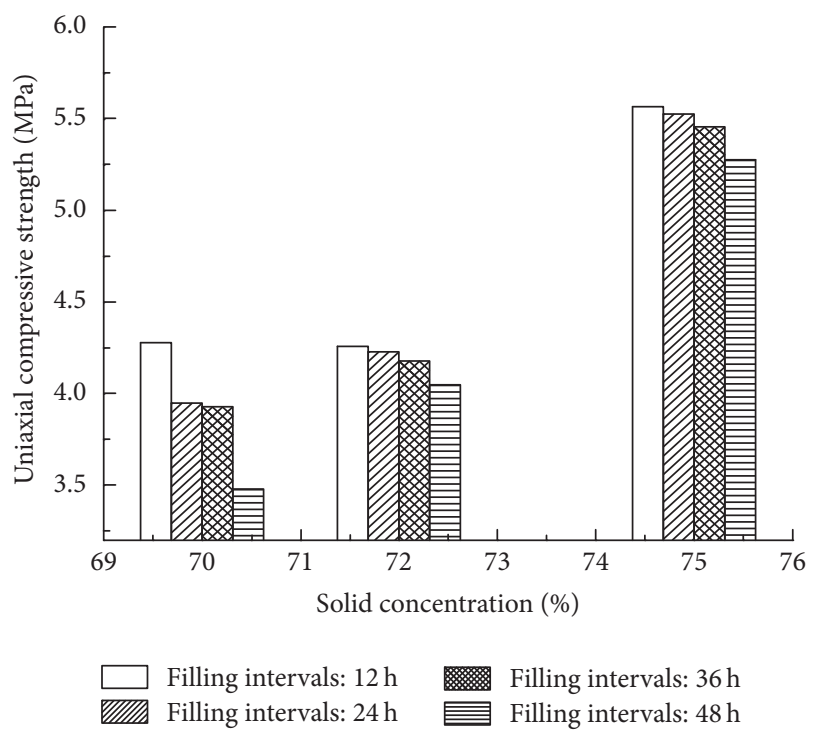

FIGURE 6: Relationship between concentration and UCS values.

a decrease of $111.45 \%$. When the concentration is $72 \%$, the strength values are, respectively, 4.18 MPa and 4.05 MPa, with a filling interval of $36 \mathrm{~h}$ and $48 \mathrm{~h}$, which shows a decrease of $3.11 \%$. While the concentration changes into $75 \%$, the strength related to $48 \mathrm{~h}$ is $5.28 \mathrm{MPa}$ and the strength related to $36 \mathrm{~h}$ is $5.46 \mathrm{MPa}$, and the latter shows a decrease of $3.29 \%$. The results above show that the influence that filling interval has on mechanical strength is obviously weakened when the concentration increases.

\section{Failure Mechanism of Stratified Backfill}

4.1. Load-Displacement Curve Analysis. According to different filling interval, the load-displacement curves are obtained under concentrations of $70 \%, 72 \%$, and $75 \%$. The curves are numbered as concentration, filling interval, and specimen number. Part of the results is shown in Figure 7 due to the limited space here.

It can be seen from the load-displacement curve in Figures $7(\mathrm{a})-7(\mathrm{c})$ that there are four loading stages considering the different filling interval:

(1) Consolidation stage: the crack is closed and the layered surface is compacted under the influence of axial stress, and the curve is concave

(2) Linear elastic stage: although the stress concentration happens in cracks, it does not reach the damage threshold value. Thus, it shows linear features

(3) Crack extension stage: the cracks extend beyond the threshold value, and the failure is intensified. The curve becomes convex

(4) Failure development stage: the cracks are developed in quantity and then reach coalescence, so the specimens are badly damaged. Different from brittle rock like granite whose strength will change sharply after the peak value, cemented backfill is still in a long period of ductile deformation 


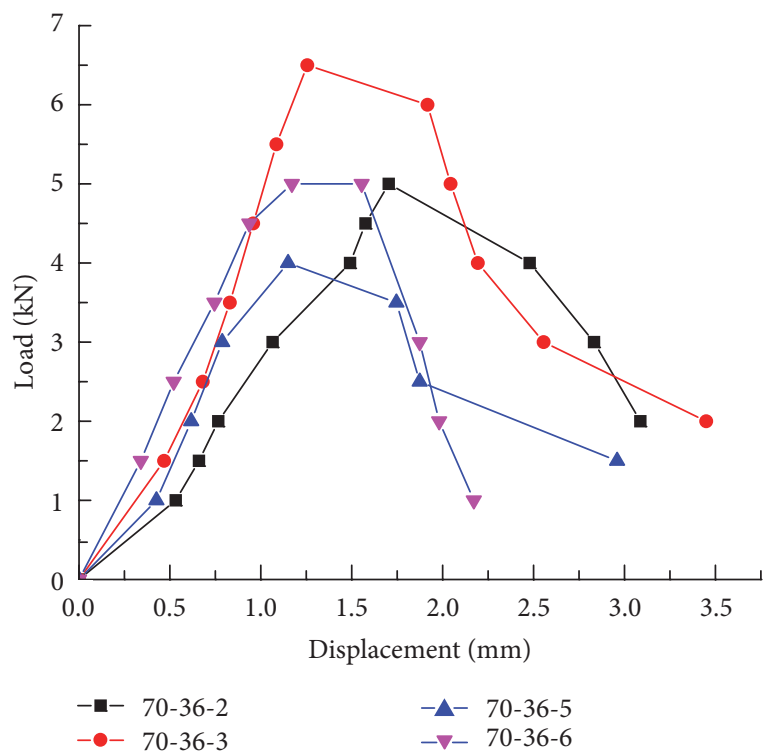

(a) $70-36$

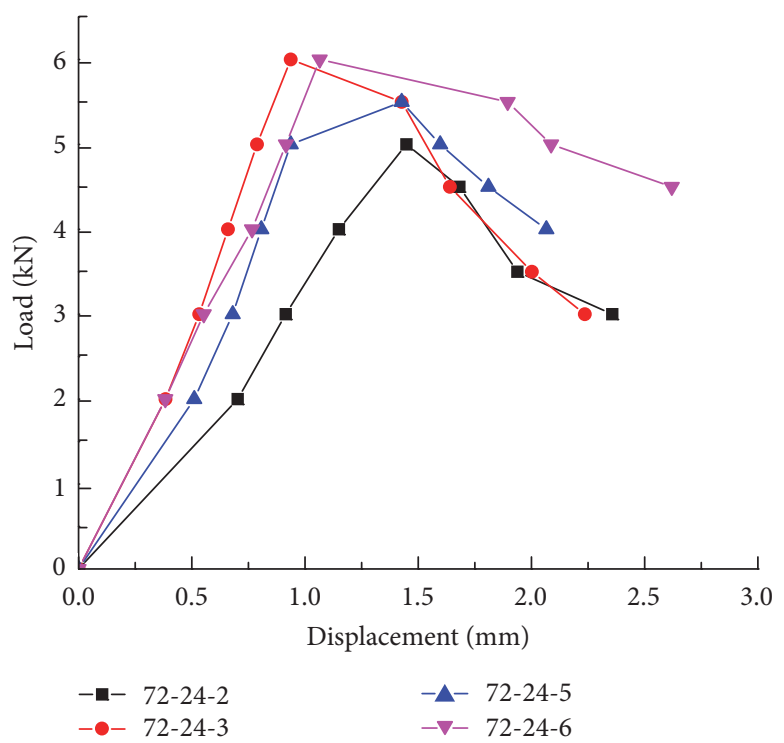

(b) $72-24$

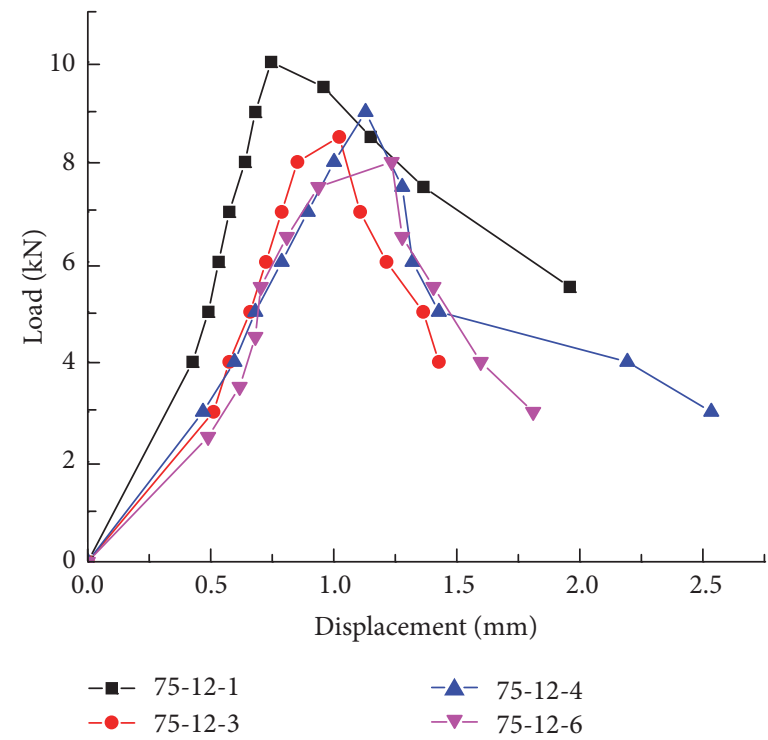

(c) $75-12$

FIGURE 7: The relationship between loading and displacement under different concentrations.

4.2. Failure Modes of Cemented Backfill. To analyze the cemented failure modes with different filling interval, typical failure specimens are chosen to be studied, which are shown in Figure 8.

It can be seen after analysis on failure modes under different filling intervals that specimens with a filling interval of $12 \mathrm{~h}$ show tension failure throughout the layered surface. Specimens of $24 \mathrm{~h}$ and $36 \mathrm{~h}$ also show tension failure in general, while the layered backfill close to the loading end shows shear failure. Specimens of $48 \mathrm{~h}$ show both tension failure and shear failure. Meanwhile, comparative analysis on specimens of $12 \mathrm{~h}, 24 \mathrm{~h}, 36 \mathrm{~h}$, and $48 \mathrm{~h}$ shows that no segregation or diastrophism appears in layered surface of the destructive specimens and the specimens are integrated overall, which is obviously different from specimens under different filling times. Thus, it can be concluded that, with the increase of filling interval, the specimens may show the failure modes of CTB transitions from tensile failure to tensile and shear failure.

\section{SEM Experiments on Specimens}

5.1. Equipment. SEM of type S-360 is used to scan the fracture of cemented backfill to figure out the microstructural features of cemented backfill after a long period time of curing.

5.2. Results and Analysis. The samples are made according to the size of $10 \mathrm{~mm} \times 10 \mathrm{~mm} \times 10 \mathrm{~mm}$ and are subjected to a carbon spray treatment for two or more times for 

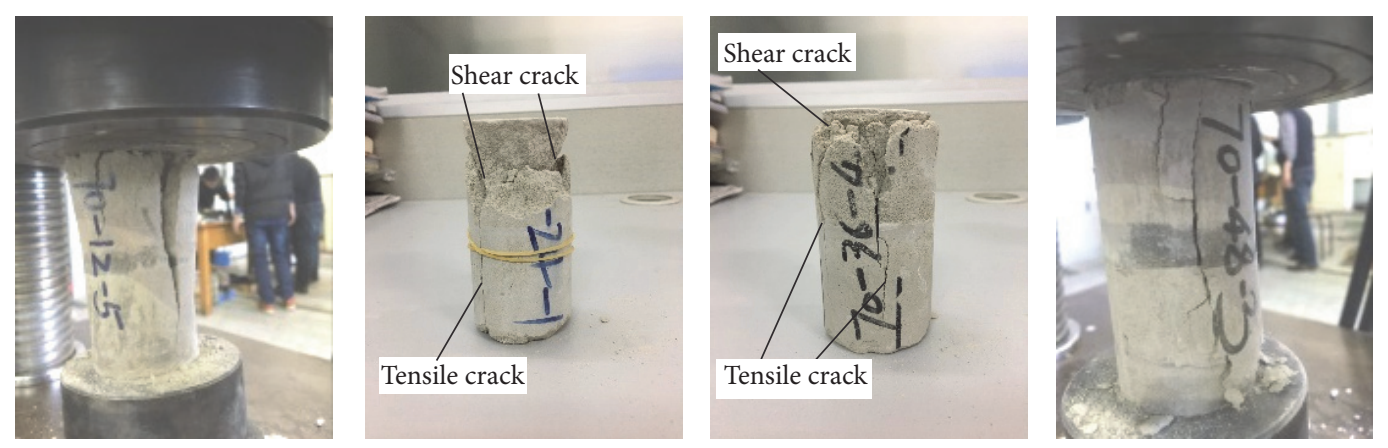

(a) Concentration $70 \%$
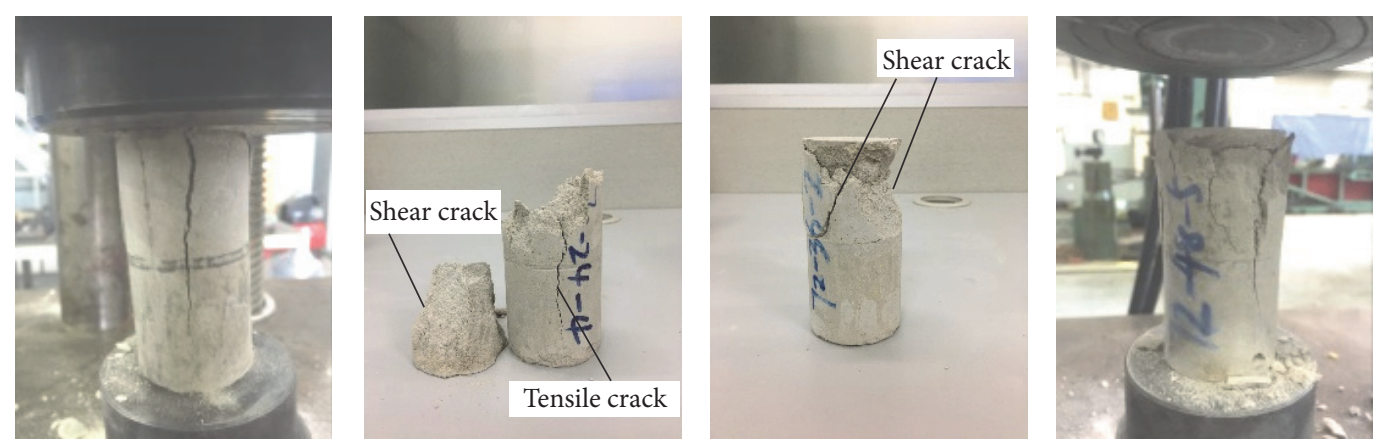

(b) Concentration $72 \%$
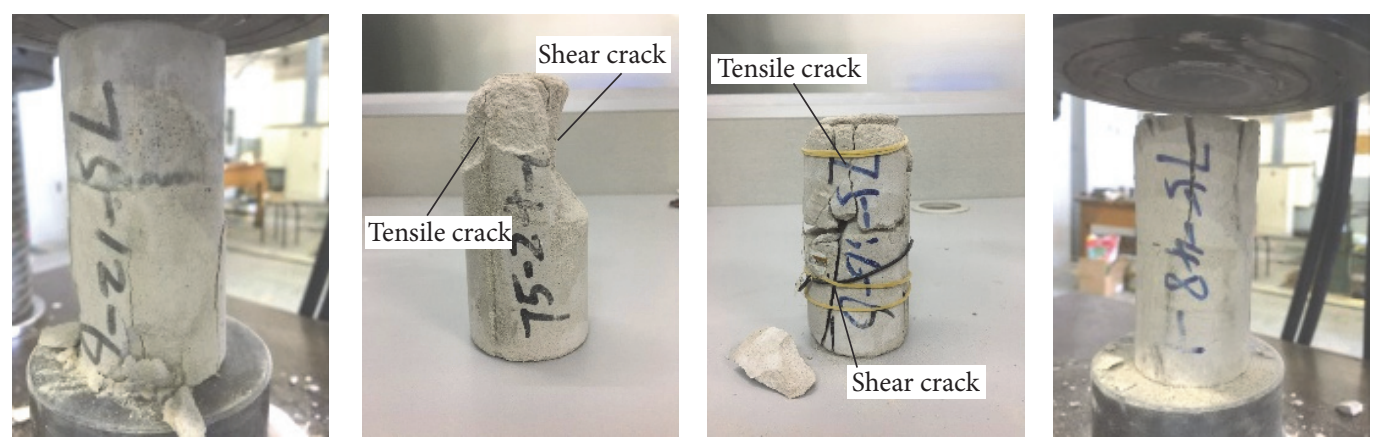

(c) Concentration $75 \%$

Figure 8: The failure modes of cemented backfill samples under different concentrations.

each sample. Then, every sample is analyzed under different magnification factors and thus the SEM photographs are obtained, which are shown in Figure 9.

Different from the fibrous C-S-H gelling agent and acicular and rod-like ettringite (AFt) crystal of the early cemented backfill, it can be seen from the SEM images that there are little acicular ettringite and a large distribution of flocculent $\mathrm{C}-\mathrm{S}-\mathrm{H}$ gelling agent in cemented backfill of $60 \mathrm{~d}$. Besides, the flocculent gelling agent is much denser, which indicates that hydration reaction happens between tricalcium silicate and dicalcium silicate, and only a little calcium aluminate (C3A) takes part in it. Also, there are still some gaps.

\section{Conclusion and Prospect}

Laboratory tests are conducted considering both filling interval and concentration, and the results are as follows:

(1) The peak compressive strength shows a trend of decrease as the filling interval increases; the compressive strength of cemented backfill grows with the increase of concentration when the filling interval remains unchanged. The peak compressive strength and filling interval meet the polynomial distribution function.

(2) There are four stages during the loading process of the cemented backfill specimens under different filling intervals, that is, consolidation stage, linear elastic stage, crack extension stage, and failure development stage. With the increase of filling interval, the specimens may show a failure mode of tension-tension and shear-shear, and no segregation or diastrophism appears in layered surface of the destructive specimens. Besides, the specimens are integrated overall.

Currently, being limited by the continuously pulpmaking capacity of the filling station, giant goaf cannot be filled at once. So it is necessary to consider the influence that filling interval has on mechanical properties. Based on the filling condition of a gold mine in Shandong, primary 


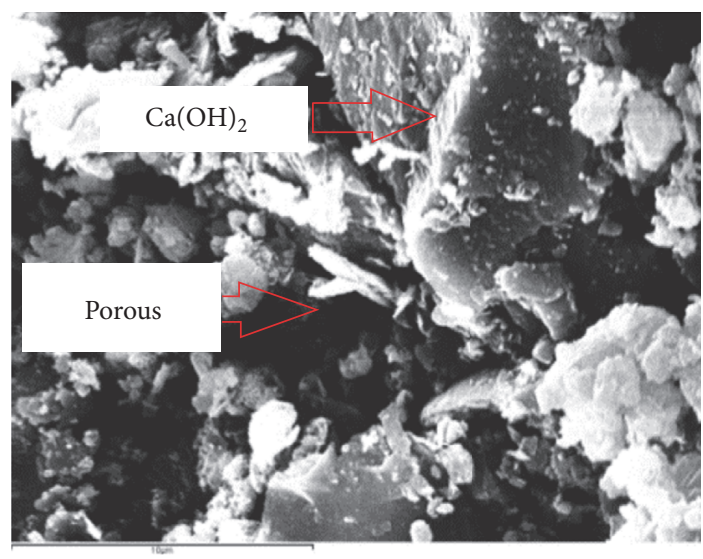

(a) Cement-sand ratio 1:6, concentration 70\%

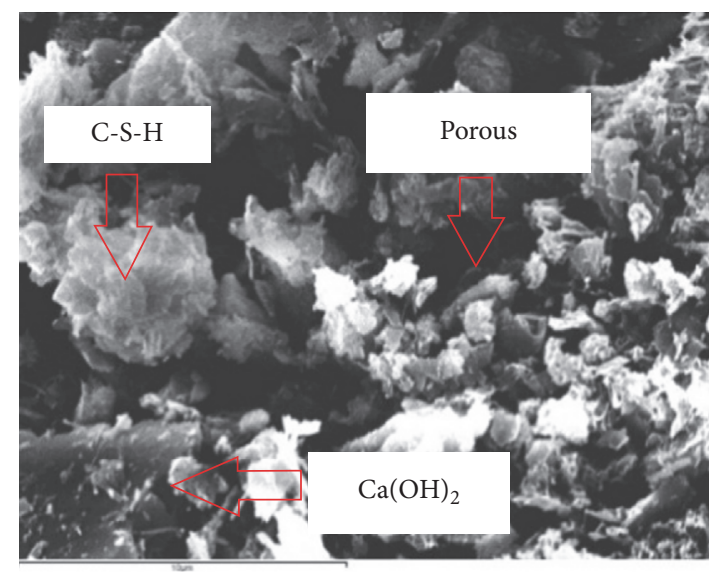

(b) Cement-sand ratio 1:6, concentration $75 \%$

FIGURE 9: SEM image of cemented tailing backfilling.

tests are conducted on two-layered cemented backfill under four kinds of filling intervals. So there are still many imperfections. Future researches may focus on considering more stratification, different filling interval, and structural factors like angles of filling working surfaces to explore the influence those factors have on mechanical properties.

\section{Competing Interests}

The authors declare that they have no competing interests.

\section{Acknowledgments}

This work was financially supported by the National Natural Science Foundation of China under Contract no. 51374033. The authors also gratefully acknowledge the members of Group Song for their technical support.

\section{References}

[1] W.-D. Song, S. Cao, J.-X. Fu, G.-J. Jiang, and F. Wu, "Sensitivity analysis of impact factors of pillar stability and its application," Rock and Soil Mechanics, vol. 35, no. 1, pp. 271-277, 2014.

[2] S. Cao, C.-F. Du, C.-P. Mu, and Y.-K. Lei, "UDEC-based modelling of mining surface movement due to transforming from block caving to sublevel filling and its law verification," Rock and Soil Mechanics, vol. 36, no. 6, pp. 1737-1751, 2015.

[3] S. Cao, W. Song, D. Deng, Y. Lei, and J. Lan, "Numerical simulation of land subsidence and verification of its character for an iron mine using sublevel caving," International Journal of Mining Science and Technology, vol. 26, no. 2, pp. 327-332, 2016.

[4] P. Lalan, A. Dauzères, L. De Windt et al., "Impact of a $70^{\circ} \mathrm{C}$ temperature on an ordinary Portland cement paste/claystone interface: an in situ experiment," Cement and Concrete Research, vol. 83, pp. 164-178, 2016.

[5] M. Kamali and A. Ghahremaninezhad, "An investigation into the hydration and microstructure of cement pastes modified with glass powders," Construction and Building Materials, vol. 112, pp. 915-924, 2016.
[6] D. Wu, G. Sun, and Y. Liu, "Modeling the thermo-hydrochemical behavior of cemented coal gangue-fly ash backfill," Construction and Building Materials, vol. 111, pp. 522-528, 2016.

[7] S. Cao, C.-F. Du, Y.-Y. Tan, and J.-X. Fu, "Mechanical model analysis of consolidated filling pillar using stage-delayed backfill in metal mines," Rock and Soil Mechanics, vol. 36, no. 8, pp. 2370-2376, 2015.

[8] B. Ercikdi, T. Yilmaz, and G. Külekci, "Strength and ultrasonic properties of cemented paste backfill," Ultrasonics, vol. 54, no. 1 , pp. 195-204, 2014.

[9] S. Chen, X. Liu, Y. Han et al., "Experimental study of creep hardening characteristic and mechanism of filling paste," Chinese Journal of Rock Mechanics and Engineering, vol. 35, no. 3, pp. 570-578, 2016.

[10] D. Li, G.-R. Feng, Y.-X. Guo et al., "Analysis on the strength increase law of filling material based on response surface method," Journal of China Coal Society, vol. 41, no. 2, pp. 392398, 2016.

[11] W. Xu, Y. Wang, P. Dang et al., "Precursors to compression failure of cemented backfill mass based on the multiparameter method," Rock and Soil Mechanics, vol. 37, no. 2, pp. 399-406, 2016.

[12] G. Ma, Z. li, X. Yi, and L. Guo, "Macro-meso experiment of fober-reinforced cement paste filling material," Journal of Beijng University of Technology, vol. 42, no. 3, pp. 406-412, 2016.

[13] S.-J. Cai, Mine Filling Mechanics Foundation, Metallurgical Industry Press, Beijing, China, 2009.

[14] S. Cao, W. Song, G. Xue et al., "Test of strength reduction of cemented tailing filling considering layering character," Rock and Soil Mechanics, vol. 36, no. 10, pp. 2869-2876, 2015. 

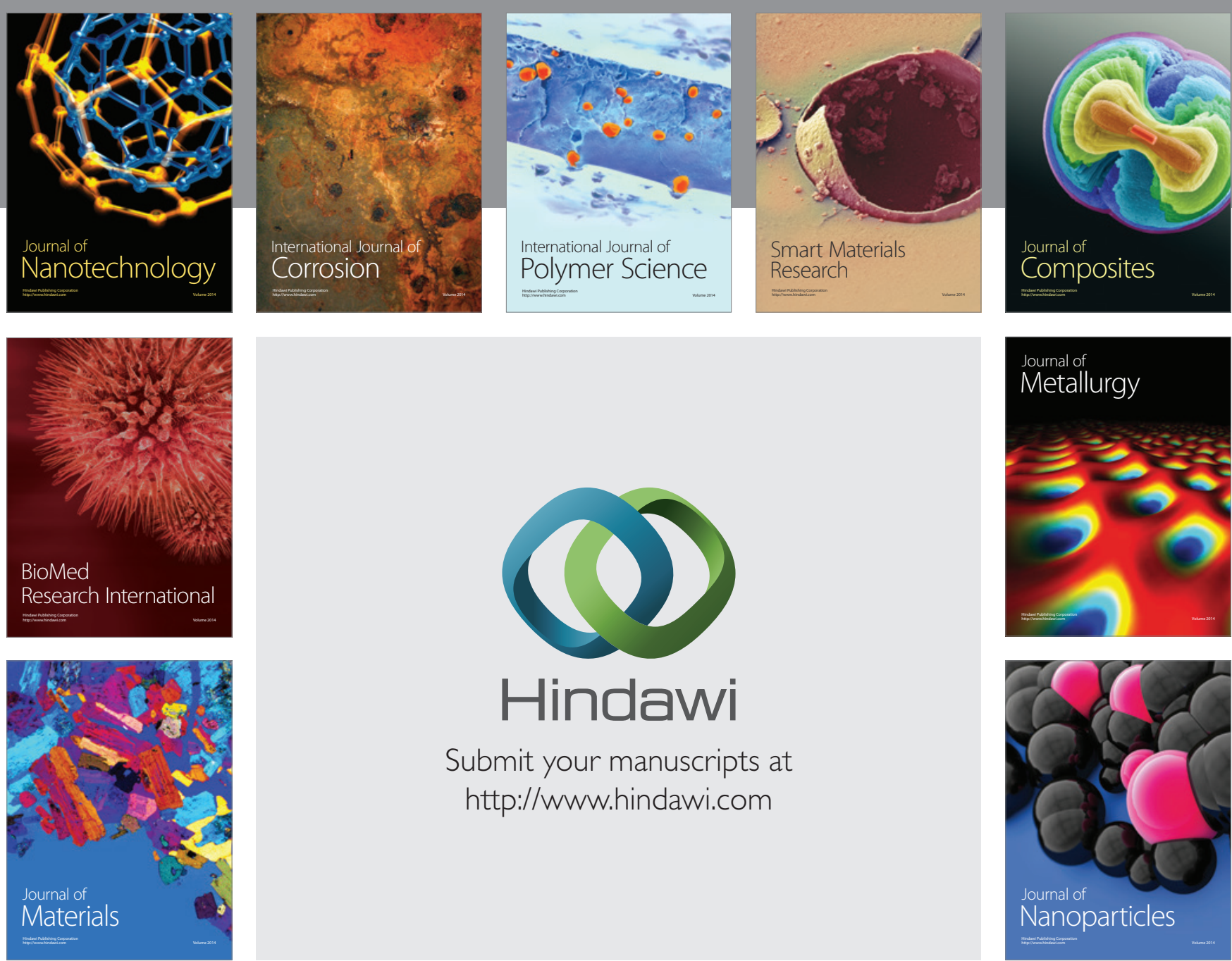

\section{Hindawi}

Submit your manuscripts at

http://www.hindawi.com

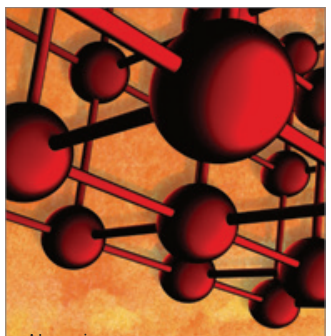

Materials Science and Engineering
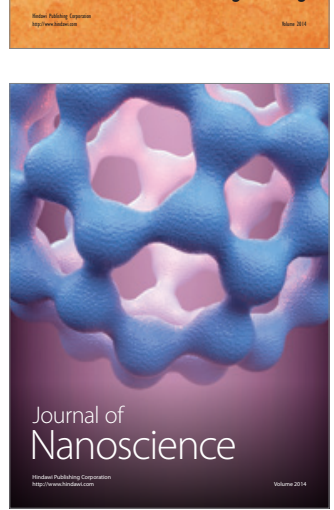
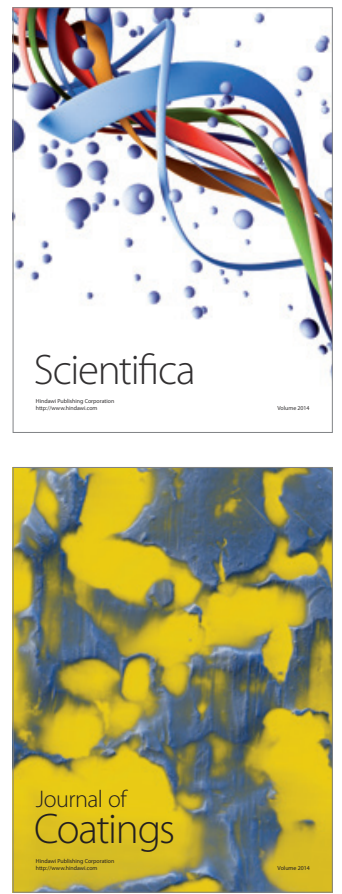
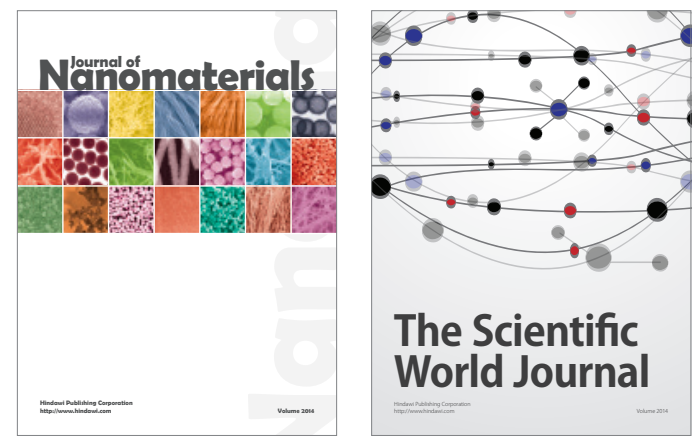

The Scientific World Journal
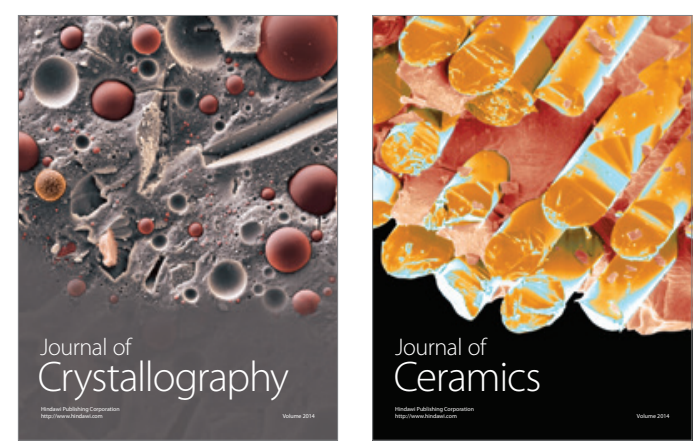
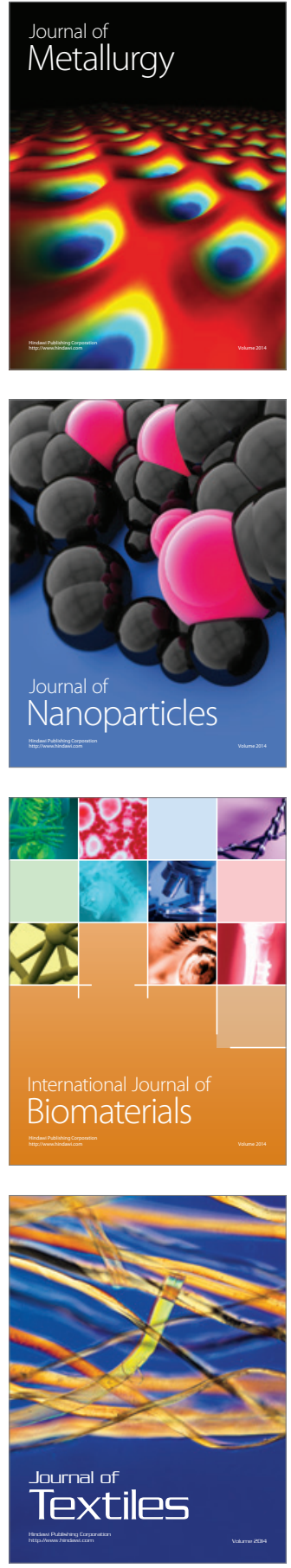